\title{
AÇÕES DE MARKETING PARA UMA AGÊNCIA DE VIAGENS DA CIDADE DE CASCAVEL - PARANÁ
}

\author{
Thiago Pecorari Lange ( Universidade do Estado Santa Catarina - UDESC ) thiagolplange@gmail.com \\ Valdésio Benevenutti ( Universidade do Estado de Santa Catarina - UDESC ) valdesio.benevenutti@udesc.br
}

\section{Resumo}

O setor de turismo vem sofrendo grandes mudanças devido a rápida evolução da internet. Com isto, o consumidor final tem acesso as ferramentas que antes eram acessíveis apenas pelas agências de viagens. Este trabalho foi desenvolvido em uma agência de viagens da cidade de Cascavel, no Paraná, e teve como objetivo propor ações de marketing para aumentar a participação da empresa no mercado e criar, ao mesmo tempo, um relacionamento mais próximo com os clientes. Para o desenvolvimento do trabalho foi realizado uma coleta de dados por meio de uma entrevista com os proprietários da empresa para entender como ela está estruturada, quais são suas limitações e como está desenvolvendo o marketing de seus produtos e serviços. Após a entrevista e a revisão bibliográfica, informações obtidas foram utilizadas para propor oito ações de marketing e com o auxílio da ferramenta 5W2H foi criado um plano de ação detalhado para a implantação de cada uma delas.

Palavras-Chaves: Agência de viagens, Marketing, Turismo.

\section{Introdução}

Com a rápida evolução e popularização da internet, o setor de turismo vem sofrendo grandes mudanças, por exemplo: a internet trouxe ao consumidor final o acesso a ferramentas que antes eram exclusivas das agências de viagens. Segundo o estudo da competitividade do turismo brasileiro realizado pelo Mistério do Turismo, com a difusão da tecnologia da informação, o setor vem sofrendo uma transformação no sentido de desintermediação e reintermediação. Com essas mudanças, a conexão entre provedores e operadores de turismo e consumidor tem sido feita de forma direta, sem a intermediação de uma agência de viagens. Esta por sua vez passa a atuar como consultoria e agenciamento para atender a um determinado perfil de consumidor (BRASIL, 2007).

Segundo a pesquisa de Barros (2005), as agências de viagens no Brasil estão sendo pressionadas pela redução das comissões das companhias aéreas, pela concorrência das agências virtuais e pela ampla disponibilidade de informações na internet acerca de destinos e 
produtos turísticos. O mercado de turismo exige cada vez mais qualidade e menor custo, e o nível de competição tem se intensificado ao longo do tempo (SCARPIN et al, 2011). Considerando o cenário agressivo que as agências de viagens estão vivendo, quais são as ações de marketing que uma agência de viagens da cidade de Cascavel no Estado do Paraná deve adotar para aumentar a sua participação no mercado e enfrentar a alta competitividade?

O objetivo geral deste trabalho é propor ações de marketing para aumentar a participação da empresa no mercado ao mesmo tempo um relacionamento mais próximo com os atuais e futuros clientes.

Para que o objetivo geral seja atingido, é necessário que ele seja desdobrado nos seguintes objetivos específicos:

a) Realizar um diagnóstico da situação atual da empresa.;

b) Entender e listar as ações que a empresa vem trabalhando para promover seus serviços e como se relaciona com o publico;

c) Elaborar um plano de ações de marketing para expandir e melhorar o que já vem sendo desenvolvido pela empresa e propor novas ações de marketing para potencializar a participação no mercado.

\section{Fundamentação Teórica}

\subsection{Marketing}

Derivado do termo inglês que significa "Mercado", o marketing é definido por Richers (2000), como a intenção de entender e atender o mercado.

A American Marketing Association - AMA (2019), responsável pela representação dos profissionais de marketing dos Estados Unidos defini: "Marketing é a atividade, o conjunto de instituições e os processos para criar, comunicar, entregar e trocar ofertas que tenham valor para consumidores, clientes, parceiros e sociedade em geral".

\subsubsection{Marketing de serviços}

Para Lima (2007), o marketing de serviços tem como foco três principais dimensões: os clientes atuais e potenciais; os funcionários; e a interação cliente-prestador de serviço. O 
atendimento dessas três dimensões é essencial para que o marketing de serviço possa atingir seus objetivos.

Sobre a qualidade nos serviços Spiller (2006) cita que: "Para satisfazer as expectativas dos clientes, as organizações devem esforçar-se para melhorar seu relacionamento com eles.

O Quadro 1 apresenta as principais implicações para cada uma das características dos serviços.

Quadro 1 - Implicação das características dos serviços

\begin{tabular}{|l|l|}
\hline \multicolumn{1}{|c|}{ Característica } & \multicolumn{1}{c|}{ Implicação } \\
\hline Intangibilidade & $\begin{array}{l}\text { - Dificuldade de avaliação prévia da qualidade e dos } \\
\text { resultados. } \\
\text { - Referências de terceiros e reputação das empresas se } \\
\text { tornam elementos relevantes para o convencimento do } \\
\text { consumidor. }\end{array}$ \\
\hline Variabilidade & $\begin{array}{l}\text { - Torna difícil a mensuração de certos resultados devido as } \\
\text { condições dos prestadores de serviço. }\end{array}$ \\
\hline Inseparabilidade & $\begin{array}{l}\text { - Requer maior habilidade de relacionamento com o cliente. } \\
\text { - Cria oportunidades de diferenciação perante os } \\
\text { concorrentes. }\end{array}$ \\
\hline Perecibilidade & $\begin{array}{l}\text { - Dificulta o uso eficiente da capacidade produtiva quando a } \\
\text { demanda é intermitente. } \\
\text { - Dificulta controle da qualidade uma vez que os erros são } \\
\text { cometidos durante a prestação do serviço. }\end{array}$ \\
\hline
\end{tabular}

Fonte: Adaptado de Spiller (2006)

\subsection{Composto de Marketing}

Segundo Kotler e Keller (2012), o mix ou composto de marketing pode ser definido pelo conjunto de ferramentas de marketing que uma empresa utiliza para atingir seus objetivos de mercado.

Os 4Ps do composto de marketing são definidos por Kotler e Armstrong (2007) como:

- Produto: Combinação de bens e serviços que a empresa oferece para o mercado-alvo. Ex: Design, embalagem, garantias e devoluções;

- Preço: Quantidade de dinheiro que os clientes têm de pagar para obter o produto. Ex: Descontos, concessões e prazo de pagamento;

- Praça: Envolve as atividades da empresa que disponibiliza o produto aos consumidores-alvo. Ex: Canais, cobertura, locais e transporte; 
- Promoção: Envolve as atividades que comunicam os pontos fortes do produto e convencem os clientes-alvo a compra-lo. Ex: Promoção de vendas, propaganda e marketing direto.

Ampliando o conceito do Mix de comunicação (Promoção), Kotler e Keller (2012) afirmam que é composto por seis formas essenciais de comunicação: Propaganda, Promoção de vendas, Eventos e experiências, Relações publicas, Marketing direto e vendas pessoais. Lima (2007) afirma que essas ferramentas criam valor para os clientes fornecendo informações que os auxiliam na tomada de decisão de compra e reduzem os custos em termos de dinheiro, tempo e esforço.

\subsubsection{Propaganda}

Para Kotler e Keller (2012), propaganda é qualquer forma paga de apresentação e promoção não pessoal de ideias, mercadorias ou serviços por um anunciante identificado. Já Cobra e Zwarg (2009) define propaganda como sendo: "uma veiculação paga de uma campanha de um anunciante que visa persuadir as pessoas a comprarem seus produtos e/ou serviços".

\subsubsection{Marketing direto}

Kotler e Keller (2012) definem o Marketing Direto como a utilização de qualquer meio de comunicação com os clientes específicos e potenciais em que haja uma resposta direta. Essa comunicação pode ser feita por: correio, telefone, fax, e-mail ou internet por exemplo. Ainda para os autores, os canais de comunicação do marketing direto possuem uma característica em comum, eles são personalizados, atualizados e interativos. Isto significa que, a mensagem é personalizada para a pessoa em que é endereçada, ela pode ser preparada rapidamente e dependendo da resposta da pessoa, ela é alterada.

\subsubsection{Marketing e mídias digitais}

Para Torres (2009), a internet se tornou um ambiente de que afeta o marketing da organização de diversas formas, seja na comunicação corporativa, seja na publicidade, e continuará afetando o marketing mesmo que a organização não invista um centavo nela. Torres (2009) ainda define o marketing digital como a utilização da internet como ferramenta de marketing para a comunicação, propaganda e demais itens do composto de marketing. 
Kotler, Kartajaya e Setiwan (2017) defendem que o marketing digital não pretende substituir o marketing tradicional, que eles devem coexistir com papéis permutáveis ao longo do caminho do consumidor. Para o autor, o marketing digital é mais controlável e seu principal papel é o de promover a ação e a defesa da marca.

No Brasil, $80 \%$ dos internautas participam de alguma rede social, o que a torna um canal de marketing muito importante para qualquer estratégia, conforme Torres (2009).

\subsubsection{Marketing de relacionamento}

O marketing de relacionamento é definido por Gordon (1998, p. 31) como: "processo contínuo de identificação e criação de novos valores com clientes individuais e o compartilhamento de seus benefícios durante uma vida toda de parceria". Vavra (1993) complementa a definição como sendo o processo de garantir satisfação contínua aos indivíduos ou organizações que são clientes atuais ou que já foram clientes de uma determinada organização.

\subsection{Plano de ação através da ferramenta 5W2H}

Para Franklin e Nuss (2006), o 5W2H pode ser definido como um plano de ações resultante de um planejamento, utilizado para orientar as atividades que serão implementadas. Nakagawa (2014) aborda a ferramenta de forma flexível, afirmando que ela pode ser útil desde sua utilização para decisões simples e cotidianas quanto para suportar outras ferramentas analíticas e planos de ações envolvendo diversas decisões.

Dessa forma a ferramenta 5W2H pode ser utilizada para suportar a implantação dos planos de ações de marketing, ela ainda é definida pelo autor conforme o Quadro 2.

Quadro 1 - Método 5W2H

\begin{tabular}{|c|l|l|}
\hline \multirow{4}{*}{$\backsim$} & What (O que?) & Que ação deve ser executada? \\
\cline { 2 - 3 } & Who (Quem?) & Quem irá executar ou participar da ação? \\
\cline { 2 - 3 } & Why (Por Quê?) & Por que a ação deverá ser executada? \\
\cline { 2 - 3 } & Where (Onde?) & Onde será executada a ação? \\
\cline { 2 - 3 } & When (Quando?) & Quando a ação deve ser executada? \\
\hline \multirow{2}{*}{} & How (como?) & Como deve ser executada a ação? \\
\cline { 2 - 3 } & How much (quanto?) & Quando custará a implementação da ação? \\
\hline
\end{tabular}

Fonte: Adaptado de Lima (2007:143)

\subsection{Controle e monitoramento}


Para Kotler e Keller (2012), o controle de marketing é o processo pelo qual as empresas avaliam os efeitos de suas atividades e programas de marketing para fazer as mudanças e os ajustes necessários. Lima (2007) resume que o controle de ações de marketing consiste no acompanhamento e na avaliação dos resultados alcançados.

O processo de controle de marketing foi classificado por Kotler e Keller (2012) em quatro categorias. Os quatro tipos de controle são: Controle do plano anual, controle da lucratividade, controle da eficiência e controle estratégico. Segundo os autores nas empresas esses quatros tipos de controle se aplicam a todos os níveis da organização, onde a alta gerência define as metas que são passadas aos níveis inferiores da administração.

Ainda Kotler e Keller (2012), dividem o processo de controle de marketing em quatro etapas: primeiro a gerência estabelece as metas, então motinara-se o desempenho, determina-se as causas dos desvios no desempenho e por último tomam medidas corretivas para aproximar os resultados das metas definidas.

\section{Procedimentos metodológicos}

O desenvolvimento deste trabalho conta com 3 etapas: Pesquisa bibliográfica, estudo de caso e proposta de ações de marketing e de controle. Inicialmente, é realizado a pesquisa bibliográfica sobre os temas que servirão de base para o desenvolvimento das propostas de ações.

A segunda etapa, do estudo de caso, se deu por meio do estudo e acompanhamento da empresa. Buscou-se entender como é a estrutura organizacional da agência de viagens e sua inserção no mercado, realizando um levantamento da situação atual da empresa e das ações de marketing que vem sendo utilizadas por ela.

Por fim, é apresentado as propostas ações de marketing e de controle que foram criadas com base na revisão bibliográfica e estudo de caso. No desenvolvimento do plano de ação foram considerados os objetivos deste trabalho e as limitações de recursos da empresa.

Para coletar os dados necessários para o desenvolvimento do trabalho, foi realizado uma entrevista com os proprietários da agência de viagens. Na entrevista foram tratados assuntos que auxiliaram para um melhor entendimento da empresa, da experiência profissional de cada um e na estruturação dos processos. Desta maneira foram identificadas as limitações e 
necessidades da empresa, permitindo ao pesquisador estruturar o trabalho delimitando o problema que será analisado.

Definido o problema, como aumentar a participação do mercado e sobreviver a concorrência, foi realizado uma pesquisa bibliográfica em livros sobre marketing, gestão, serviços e o setor de turismo. Também foram consultados sites de especialistas em marketing e do setor de turismo para identificar quais ações vem sendo utilizadas pelo mercado e quais são os resultados que vêm sendo obtidos.

\section{Resultados e discussõoes}

\subsection{Apresentação da agência de viagens}

A agência de viagens está localizada na cidade de Cascavel, no oeste do estado do Paraná. Fundada no ano de 2000. A empresa conta hoje com dois proprietários e mais dois funcionários no quadro de colaboradores. As demais atividades são terceirizadas, possuindo 24 fornecedores.

A agência de viagens atua no ramo de agenciamento de turismo atendendo a pessoas físicas e jurídicas da cidade e regiões próximas. Entre os serviços oferecidos estão: Reservas de hotéis, venda de passagens aéreas, aluguel de veículos, seguro de viagem, assessoria de documentação para viagens e pacotes de turismo. A principal fonte de renda da empresa é a comissão recebida pela venda dos serviços operados pelos fornecedores.

\subsection{Plano de ação}

Serão apresentados 8 planos de ações para a promoção da agência de viagens com o objetivo de aumentar a participação do mercado e o engajamento com o publico. As ações foram planejadas de acordo com a situação atual descrita e dos recursos disponíveis pela empresa.

\subsubsection{Padronização da identidade visual}

Atualmente a agência de viagens não possui nenhum padrão visual de comunicação, utilizando apenas cartões de visitas. 
Os orçamentos solicitados são enviados aos clientes em formato digital, porém sem nenhum elemento visual e customização. Constatou-se que muitos dos orçamentos solicitados acabam sem resposta do cliente

O Quadro 3 descreve o plano desenvolvido, com os responsáveis, custos e prazos para conclusão.

Quadro 3 - Plano de ação: Padronização da identidade visual

\begin{tabular}{|c|c|c|c|}
\hline \multirow{5}{*}{ in } & What & O que? & $\begin{array}{l}\text { Criação de modelo padrão de orçamento e exposição de } \\
\text { produtos. }\end{array}$ \\
\hline & Who & Quem? & Funcionária A em conjunto com Designer terceirizado. \\
\hline & Why & Por quê? & $\begin{array}{l}\text { Criar um padrão de comunicação rico em informações e } \\
\text { elementos visuais demonstra mais profissionalismo e } \\
\text { desperta maior interesse nos clientes, buscando-se assim } \\
\text { aumentar as vendas. }\end{array}$ \\
\hline & Where & Onde? & Internet, e-mail e mídias sociais \\
\hline & When & Quando? & Novembro 2019. \\
\hline \multirow[t]{2}{*}{$\underset{\mathrm{N}}{\mathrm{T}}$} & How & Como? & $\begin{array}{l}\text { Selecionar designer e exemplos de materiais, solicitar o } \\
\text { desenvolvimento, acompanhar e validar o trabalho e } \\
\text { realizar a aplicação dos materiais criados quando } \\
\text { necessário. }\end{array}$ \\
\hline & How much & Quanto? & $\mathrm{R} \$: 855,00$. \\
\hline
\end{tabular}

Fonte: Elaborado pelos autores, 2019.

Após a conclusão da ação, o novo material estará disponível para todos os colaboradores da agência de viagens que fará seu uso e customização quando um novo produto for lançado ou orçamento solicitado.

\subsubsection{Reformulação do Website}

Hoje a empresa já conta com um website, porém ele ainda é mal utilizado, apenas servindo com catálogo online. O Quadro 4 descreve o plano de ação para a reformulação do website.

Quadro 4 - Plano de ação: Reformulação do website

\begin{tabular}{|l|l|l|l|}
\hline \multirow{2}{*}{} & What & O que? & Reformulação do website \\
\cline { 2 - 4 } & Who & Quem? & Proprietário A, Funcionário B e Terceirizado. \\
\cline { 2 - 4 } & Phy & Por quê? & $\begin{array}{l}\text { A internet é o principal meio de comunicação com os } \\
\text { clientes e é necessário ter uma presença online. É } \\
\text { necessária a atualização do site para seguir as novas } \\
\text { tendências do mercado e atender as expectativas dos } \\
\text { clientes. }\end{array}$ \\
\hline & Where & Onde? & Online \\
\hline & When & Quando? & Janeiro 2020. \\
\hline
\end{tabular}




\begin{tabular}{|l|l|l|l|}
\hline \multirow{2}{*}{$\underset{\sim}{*}$} & How & Como? & $\begin{array}{l}\text { A criação e programação do website será realizada por } \\
\text { um terceiro, porém a produção do conteúdo acerca da } \\
\text { empresa e dos serviços ficará sob a responsabilidade do } \\
\text { Proprietário A e a produção de conteúdos acerca dos } \\
\text { produtos ficará sob responsabilidade do Funcionário B. }\end{array}$ \\
\cline { 2 - 4 } & How much & Quanto? & R\$: $1.697,00$ \\
\hline
\end{tabular}

Fonte: Elaborado pelos autores, 2019

Com essas alterações esperasse obter maior engajamento do publico, aumentar a credibilidade da empresa acerca dos serviços prestados e também a exposição ao mercado.

\subsubsection{Criação de hotsites para serviços e produtos}

A criação de hotsites personalizados para cada pacote e serviço irá atrair a atenção dos clientes e oferecer argumentos convincentes para que ele efetue a compra na agência de viagens. O planejamento desta ação é descrito no Quadro 5.

Quadro 5 - Plano de Ação: Criação de hotsites.

\begin{tabular}{|l|l|l|l|}
\hline \multirow{4}{*}{} & What & O que? & Criação de hotsites para serviços e produtos. \\
\cline { 2 - 4 } & Who & Quem? & Funcionário B \\
\cline { 2 - 4 } & Why & Por quê? & $\begin{array}{l}\text { Para ampliar a divulgação dos produtos e criar maior } \\
\text { engajamento com o publico. }\end{array}$ \\
\cline { 2 - 4 } & Where & Onde? & Website \\
\cline { 2 - 4 } & When & Quando? & $\begin{array}{l}\text { Sempre que um novo produto for disponibilizado pelos } \\
\text { fornecedores. }\end{array}$ \\
\hline \multirow{2}{*}{$\underset{\sim}{*}$} & How & Como? & $\begin{array}{l}\text { Receber o material dos fornecedores, levantar } \\
\text { informações adicionais acerca do produto, desenvolver } \\
\text { uma página personalizada para o produto, promover a } \\
\text { página criada nas mídias sociais. }\end{array}$ \\
\cline { 2 - 4 } & How much & Quanto? & R00,00 por página. \\
\hline
\end{tabular}

Fonte: Elaborado pelos autores, 2019.

O valor estipulado contempla a promoção da página e o custo de materiais gráficos ou licenciamento de imagens.

\subsubsection{Mídias sociais (Instagram)}

O Instagram é uma das mídias sociais mais utilizadas pelo brasileiro. O Quadro 6 apresenta o detalhamento da ação levando em conta o desenvolvimento da parte gráfica internamente pela empresa para evitar custos adicionais. 
Após a publicação, propõe-se o uso de anúncios pagos para aumentar o alcance das publicações e um monitoramento para avaliar o desempenho de cada publicação e direcionar os futuros materiais.

Quadro 6 - Plano de ação: Mídias sociais (Instagram)

\begin{tabular}{|l|l|l|l|}
\hline \multirow{2}{*}{} & What & O que? & Estratégia de Publicação para Instagram \\
\cline { 2 - 4 } & Who & Quem? & Funcionária A \\
\cline { 2 - 4 } & Why & Por quê? & $\begin{array}{l}\text { Aumentar a interação da empresa com o publico na rede } \\
\text { social, buscando aumentar o engajamento e o número de } \\
\text { vendas. }\end{array}$ \\
\hline \multirow{2}{*}{$\underset{*}{*}$} & Where & Onde? & Instagram \\
\cline { 2 - 4 } & When & Quando? & Semanalmente a partir de janeiro de 2020. \\
\hline & Como? & $\begin{array}{l}\text { Entender melhor o perfil do publico no Instagram, } \\
\text { desenvolver conteúdos relevantes e de promoção, } \\
\text { impulsionar as publicações, avaliar o desempenho. }\end{array}$ \\
\cline { 2 - 4 } & How much & Quanto? & $\mathrm{R} \$: 40,00$ por publicação. \\
\hline
\end{tabular}

Fonte: Elaborado pelos autores, 2019.

\subsubsection{Mídias sociais (Facebook)}

O Facebook tem se mostrado um canal de comunicação bastante ativo para a empresa, que regularmente recebe pedidos de cotações e dúvidas sobre os serviços prestados. O Quadro 7 apresenta o plano de ação para o Facebook e ele é similar a estratégia que será desenvolvida para o Instagram, porém elas se diferem no formato do conteúdo e na linguagem de comunicação para interagir com o publico.

Quadro 7 - Plano de ação: Mídias sociais (Facebook)

\begin{tabular}{|c|c|c|c|}
\hline \multirow{5}{*}{ in } & What & O que? & Estratégia de publicação para Facebook \\
\hline & Who & Quem? & Funcionária A e designer terceirizado. \\
\hline & Why & Por quê? & $\begin{array}{l}\text { Aumentar o engajamento e alcance das publicações na } \\
\text { página do Facebook. }\end{array}$ \\
\hline & Where & Onde? & Facebook. \\
\hline & When & Quando? & Semanalmente a partir de janeiro de 2020. \\
\hline \multirow[t]{2}{*}{$\underset{\sim}{\sim}$} & How & Como? & $\begin{array}{l}\text { Entender o perfil do publico no Facebook, criar pauta } \\
\text { para publicação, em conjunto com o designer } \\
\text { desenvolver o material gráfico, publicar, impulsionar e } \\
\text { analisar o desempenho da postagem. }\end{array}$ \\
\hline & How much & Quanto? & $\begin{array}{l}\mathrm{R} \$: 100,00 \text { para o designer }+\mathrm{R} \$ 40,00 \text { para impulsionar a } \\
\text { publicação. }\end{array}$ \\
\hline
\end{tabular}

Fonte: Elaborado pelos autores, 2019. 
A análise de desempenho das publicações também é fundamental para entender o comportamento dos consumidores e poder criar conteúdo que seja mais relevante pare eles.

\subsubsection{E-mail marketing}

O e-mail marketing é uma ferramenta de marketing direto, pois cria um canal direto de comunicação com o consumidor. No Quadro 8 é detalhada a ação.

Quadro 8 - Plano de ação: E-mail marketing.

\begin{tabular}{|l|l|l|l|}
\hline \multirow{4}{*}{} & What & O que? & Criar campanhas de e-mail marketing \\
\cline { 2 - 4 } & Who & Quem? & Funcionária B. \\
\cline { 2 - 4 } & Why & Por quê? & $\begin{array}{l}\text { Criar um canal direto com o consumidor para divulgar } \\
\text { informações relevantes, promoções e novos serviços. }\end{array}$ \\
\cline { 2 - 4 } & Where & Onde? & E-mail e internet. \\
\cline { 2 - 4 } & When & Quando? & Quinzenalmente a partir de janeiro de 2020. \\
\hline \multirow{2}{*}{$\underset{\sim}{*}$} & How & Como? & $\begin{array}{l}\text { Criar conteúdo de e-mail com dicas de viagens e } \\
\text { produtos e encaminhar para a lista de clientes } \\
\text { selecionados. }\end{array}$ \\
\cline { 2 - 4 } & How much & Quanto? & $\begin{array}{l}\text { Ação sem custo financeiro, sendo necessário apenas o } \\
\text { investimento de 2 horas de trabalho para a criação do } \\
\text { conteúdo. }\end{array}$ \\
\hline
\end{tabular}

Fonte: Elaborado pelos autores, 2019.

Também será utilizado deste canal de comunicação para divulgar as promoções e ofertas.

\subsubsection{Canais de atendimento e relacionamento com o cliente}

A falta de informação e dificuldade no acesso a elas pode levar o cliente a buscar outra empresa para sanar suas dúvidas e fornecer o serviço. O Quadro 9 propõe a criação de uma nova seção no website da empresa onde todo o conteúdo será publicado.

Quadro 9 - Plano de ação: Canais de atendimento e relacionamento com o cliente.

\begin{tabular}{|l|l|l|l|}
\hline \multirow{2}{*}{} & What & O que? & Seção de relacionamento dos clientes \\
\cline { 2 - 4 } & Who & Quem? & Proprietário B \\
\cline { 2 - 4 } & Why & Por quê? & $\begin{array}{l}\text { Aumentar a confiança dos clientes na empresa e } \\
\text { solucionar eventuais casualidades para garantir a } \\
\text { qualidade dos serviços prestados. }\end{array}$ \\
\hline \multirow{2}{*}{$\underset{*}{*}$} & Where & Onde? & Website. \\
\cline { 2 - 4 } & When & Quando? & Março 2020. \\
\hline \multirow{2}{*}{ How } & Como? & $\begin{array}{l}\text { Criar um canal que consolide as principais dúvidas dos } \\
\text { clientes e que permita uma interação rápida com um } \\
\text { agente para sanar questionamentos adicionais. } \\
\text { Periodicamente realizar a revisão das questões e incluir }\end{array}$ \\
\hline
\end{tabular}




\begin{tabular}{|l|l|l|l|}
\hline & & $\begin{array}{l}\text { novas conforme clientes entrem em contato com a } \\
\text { empresa com novas dúvidas. }\end{array}$ \\
\cline { 2 - 4 } & How much & Quanto? & $\begin{array}{l}\text { Alocação de horas de trabalho para a criação, 8 horas, e } \\
\text { manutenção do conteúdo, 2 horas semanais. }\end{array}$ \\
\hline
\end{tabular}

Fonte: Elaborado pelos autores, 2019.

Este canal proposto deve ser dinâmico e atualizado constantemente. As informações ali presentes podem perder a relevância e novos tópicos surgem com bastante frequência.

\subsubsection{Campanhas de tráfego pago}

No Quadro 10 está descrito o plano de ação para a criação de campanhas de tráfego pago.

Quadro 102 - Plano de ação: Campanhas de tráfego pago

\begin{tabular}{|c|c|c|c|}
\hline \multirow{5}{*}{ in } & What & O que? & Criação de campanhas de tráfego pago \\
\hline & Who & Quem? & Proprietário B e Funcionário B \\
\hline & Why & Por quê? & $\begin{array}{l}\text { O uso de campanhas de tráfego pago atrairá mais } \\
\text { usuários ao site e assim gerar maior visibilidade da } \\
\text { marca. }\end{array}$ \\
\hline & Where & Onde? & Internet, website e hotsites. \\
\hline & When & Quando? & Abril 2020. \\
\hline \multirow{2}{*}{$\stackrel{\mathbb{N}}{\sim}$} & How & Como? & $\begin{array}{l}\text { Identificar palavras-chave de busca e conteúdo que possa } \\
\text { atender a expectativa dos usuários, criar campanhas para }\end{array}$ \\
\hline & How much & Quanto? & $\begin{array}{l}\mathrm{R} \$: 200,00 \text { por campanha para validar, podendo ser } \\
\text { estendida conforme performance. }\end{array}$ \\
\hline
\end{tabular}

Fonte: Elaborado pelos autores, 2019.

O orçamento disponibilizado para cada campanha servirá para avaliar a performance, se está havendo busca pelo conteúdo criado e se ele está atendendo as expectativas.

\section{Considerações finais}

Foram propostas 8 ações de marketing que visaram ampliar a visibilidade da empresa e criar uma maior conexão com o mercado e atuais clientes. As ações englobaram os conceitos do mix de propaganda e do marketing de relacionamento, utilizando ferramentas de marketing direto, promoção e mídias digitais. Para as ações listadas, foram desenvolvidos os planos de ações utilizando a ferramenta 5W2H para planejar a implantação de forma clara e objetiva.

O estudo de caso e as propostas de ações foram bem recebidos pelos proprietários e funcionários da agência de viagens. Para eles, o desenvolvimento deste trabalho trouxe um melhor entendimento da situação atual da empresa e também trouxe a oportunidade de 
expandir a visão para a necessidade de novas ações para enfrentar a alta competitividade do mercado.

\section{REFERÊNCIAS}

AMA. Definitionsof Marketing.2019. Disponível em: <https://www.ama.org/the-definition-of-marketing/>. Acesso em: 28/09/2019.

BARROS, F. (2005). O alinhamento estratégico da utilização da internet em agências de viagens e turismo operando no brasil. Dissertação, Mestrado em Administração, Instituto COPPEAD de Administração, Universidade Federal do Rio de Janeiro, Rio de Janeiro, RJ, Brasil.

BRASIL. MINISTÉRIO DO TURISMO. Estudo da competitividade do turismo brasileiro: o segmento de agências e operadoras de viagens e turismo. Brasília: MTur, 2007.

COBRA, M.; ZWARG, F.A. Marketing de Serviços: conceitos e estratégias. São Paulo: McGraw-Hill, 2009.

FRANKLIN, Yuri; NUSS, Luiz Fernando. Ferramenta de Gerenciamento. Resende: AEDB, Faculdade de Engenharia de Resende, 2006.

GORDON, Ian. Marketing de relacionamento: estratégias, técnicas e tecnologias para conquistar clientes e mantê-los para sempre. São Paulo: Futura, 1998.

KOTLER, P., KARTAJAYA, H., SETIWAN, I. Marketing 4.0: do tradicional ao digital. Rio de Janeiro: Sextante, 2017.

KOTLER, P.; ARMSTRONG, G.; Princípios de marketing. 12ed. São Paulo: Pearson Prentice Hall, 2007.

KOTLER, P.; KELLER K.L. Administração de marketing. 14 ed. São Paulo: Pearson, 2012.

LIMA, et al. Gestão de Marketing. 8. ed. Rio de Janeiro: Editora FGV, 2007.

NAKAGAWA, Marcelo. Ferramenta 5W2H - Plano de Ação para Empreendedores. Globo, 2014.

RICHERS, Raimar. Marketing: uma visão brasileira. São Paulo: Negócio Editora, 2000.

SCARPIN, M.; MONDINI, L.; NEUMANN, M.; MACHADO, D. (2011). Desenvolvimento de um ambiente propício para inovação no setor de serviços: uma análise em empresas de serviços contábeis do Vale do Itajaí - SC. RCO - Revista De Contabilidade E Organizações, 5 (13), 91-108.

SPILLER, Eduardo Santiago et al. Gestão de serviços e marketing interno. 3. ed. Rio de Janeiro: Editora FGV, 2006.

TORRES, C. A bíblia do marketing digital: tudo o que você queria saber sobre marketing e publicidade na internet e não tinha a quem perguntar. São Paulo: Novatec, 2009.

VAVRA, Terry G. Marketing de relacionamento (aftermarketing). São Paulo: Atlas, 1993. 